\title{
Sailing towards digitalization when it doesn't make cents? Analysing the Faroe Islands' new digital governance trajectory
}

\author{
Keegan McBride \\ Tallinn University of Technology, Ragnar Nurkse Department of Innovation and \\ Governance, Tallinn, Estonia \\ keegan.mcbride@taltech.ee
}

\begin{abstract}
Talgildu Føroyar is a project-based temporary organization, funded from 2015 through 2020, tasked with spearheading the Faroe Islands' digital governance movement. As a small, subnational island jurisdiction (SNIJ), the government of the Faroe Islands with its population of 50,000 believes that digitalization will lead to decreased government costs, a reduction in bureaucracy, a more efficient government, and empowered citizens. The objective of this paper is twofold: firstly, to provide an accurate narrative of how the digitalization of the Faroe Islands has unfolded and, secondly, to explore the different beliefs and motivations held by stakeholders that have driven the digitalization of the Faroe Islands. The research is inductive in nature and was conducted following a descriptive case studybased methodology drawing primarily from 23 semi-structured interviews conducted over a three-week field visit to the Faroe Islands and supported by secondary evidence sources such as government policy documents and internal government reports. The paper outlines the primary barriers facing digitalization in the Faroe Islands, and finds that while digitalization is unlikely to be cost effective, it does have the potential to provide other tangible benefits such as a revitalized ICT sector.
\end{abstract}

Keywords: digitalization, Faroe Islands, governance, small states, subnational island jurisdictions (SNIJs), Small States, Faroe Islands

https://doi.org/10.24043/isj.93 • Received March 2019, accepted August 2019

(C) 2019-Institute of Island Studies, University of Prince Edward Island, Canada.

\section{Introduction}

The Faroe Islands are a small, isolated, subnational island jurisdiction (SNIJ) that belongs to the Kingdom of Denmark. SNIJs "manifest diverse expressions of governance within typically asymmetric relationships with a much larger state," often leading to a unique power relationship and political discourse (Baldacchino \& Milne, 2006). This unique relationship often manifests as a balancing act between an SNIJ's desire for increased levels of sovereignty and the benefits provided by the larger state, such as funding (the Faroe Islands receive an annual block grant of $€ 86$ million) (Government of the Faroe Islands, 2019) and national security. The Faroe Islands are no different, and this struggle is evident in the makeup of their political system where parties are classified along three dimensions rather than two (Hoff \& 
West, 2008): socially left/right, economically left/right, and independence for/against. Geographically, the Faroe Islands are isolated (Figure 1), rural in nature, spread out over 18 islands, and boasting a small, largely homogenous, population of around 51,000 people.

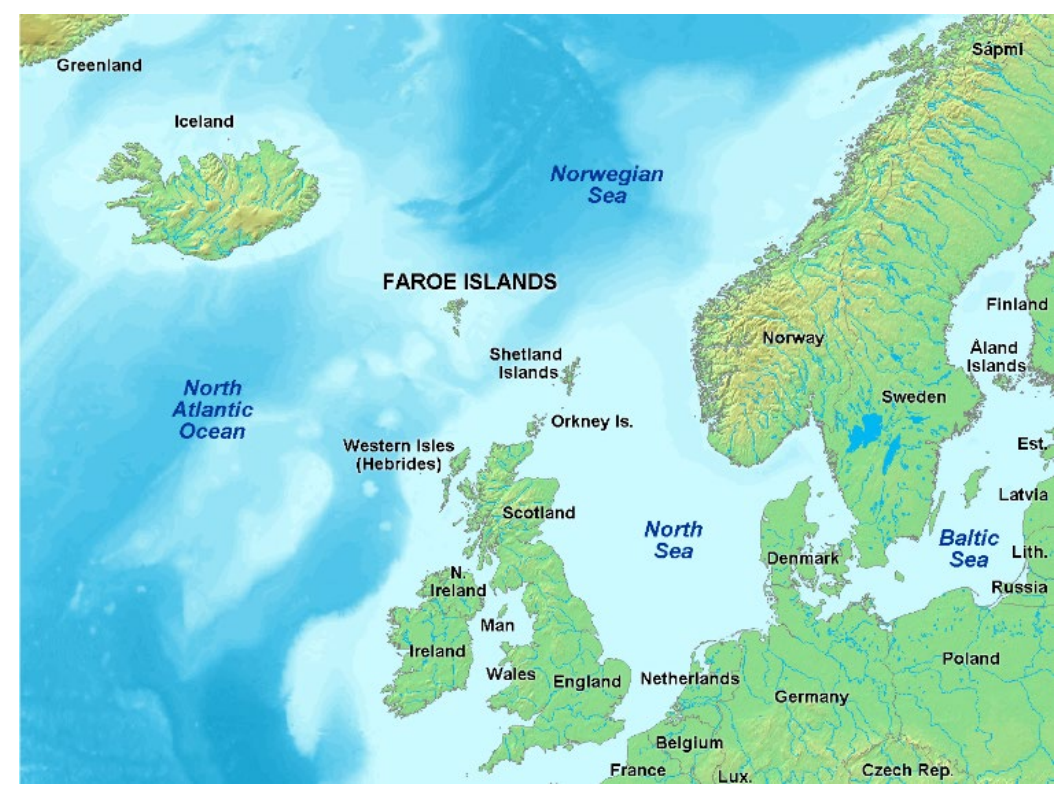

Figure 1: Geographical location of the Faroe Islands. Source: List, 2005. Retrieved from https://commons.wikimedia.org/wiki/File:Map of faroe islands in europe - english caption.png

Though part of the Kingdom of Denmark, the Faroes have had some degree of selfrule and autonomy since the passing of the Home Rule Act in 1948, which delegated most governance-related activities to Faroese institutions (Government of the Faroe Islands, 2019). Interestingly, though part of the Kingdom of Denmark, the Faroes are not a member of the EU or EEA. As it currently stands, the Faroese government is responsible for most areas of government, excluding national defence, policing and prisons, immigration, aviation, and financial regulation (Government of the Faroe Islands, 2019). As the Faroe Islands have been increasingly taking control over their own affairs, effort has been spent on increasing their institutional capacity and domestic governance mechanisms. Being a small state, there are some idiosyncrasies that are present that make a bureaucracy in the traditional Weberian sense impractical (Baker, 1992). Thus, methods are often sought to make governing more effective in a small state context. One of the newest approaches pursued in the Faroe Islands to potentially improve their governance capacity and effectiveness has been strategic investments in government digitalization. In order to better drive the digitalization process, a new projectbased temporary organization was created within Gjaldstovan (the Faroe Government Institution for Accounting, Finance, and IT) and given the name Talgildu Føroyar ('Digital Faroe Islands'). The project was allocated funding from 2015 to 2020. Though the project was initially temporary in nature, there is an ongoing debate on whether to formalize Talgildu Føroyar as a department within Gjaldstovan to manage continued future digitalization efforts.

Though still ongoing, this project presents an interesting opportunity to study the digitalization efforts of a small state throughout the process rather than the end result of digitalization and to better understand the motivations of stakeholders and drivers behind the process, before any expected benefits or results have actualized. In order to better understand 
this process, this paper adopts a descriptive and narrative case study-based approach to achieve two primary goals. Firstly, it aims to provide an accurate narrative of how the digitalization of the Faroe Islands has unfolded and, secondly, it aims to explore the different beliefs and motivations held by stakeholders that have driven digitalization.

In order to address these goals, the paper starts with a brief overview of the peculiarities associated with the governance of small states and territories, as well as the different understandings of digital governance in today's academic discourse. Following this, the narrative of the Faroe Islands' digital governance journey so far is relayed. The paper then proceeds into a discussion that critically compares and analyzes the competing motivations for pursuing digital governance in the Faroe Islands.

The research in this paper is likely to be of interest to both scholars of e-Government and for those within island studies. With regard to e-Government literature, this research is unique in that it presents an interpretive rather than positivist approach to the study of digitalization and, additionally, highlights the importance of context and narratives when conducting research on e-Government initiatives. For scholars within the domain of island studies, this research provides insights into the relationship between islandness, smallness, and digitalization. Thus, the main contribution of this paper is its description of digitalization within a small state and a greater in-depth understanding of how such a process unfolds.

\section{Small territories, digitalization, making sense of the gap}

The issue of size and defining 'smallness' is much debated within the current literature on small states and territories. A recent approach to the issue of 'size' has been to take a continuumbased (rather than an absolute) approach, in which the smaller the state, the more likely it is to exhibit governance and institutional traits associated with smallness (Bray, 1991, ctd. in Randma-Liiv \& Sarapuu, 2019). As the Faroe Islands have a population of around 51,000, it may be considered a small state, but, more specifically, also a micro-state and, taking into account the continuum approach, is likely to exhibit and share traits with other small territories.

Over the years, it has become increasingly clear that small territories are not the same as larger territories, and the study of them needs to be approached in a different manner. Whereas larger territories can have a Weberian bureaucracy with professionalized, neutral, skilful, and specialized bureaucrats, this is for the most part impossible in small territories (Murray, 1981; Pirotta, Wettenhall, \& Briguglio, 2001). There are many reasons this occurs, but most can be traced back to small population size, which places a natural limit on the size of the bureaucracy (Murray, 1981; Richards, 1982) and in turn requires policymakers and administrators to function more as generalists than specialists (Sarapuu, 2010). Another side effect of having a small population is that the cost of governing per person is higher than in larger territories due to economies of scale. Outside of these constraints directly associated with a small population, small territories are economically different than larger territories (Grydehøj, 2018), which may lead to difficulty when it comes to building administrative capacity (Murray, 1981) or procuring innovation due to small internal markets (Kattel, Randma-Liiv, \& Kalvet, 2011). These contextual factors all potentially make the alreadydifficult process of governing even more so. Small territories may thus be especially interested in reforms, administrative procedures, or innovations that target or aim to improve effectiveness and efficiency. 
Digital governance is one such innovation that has been proposed as a potential solution. For example, Awan (2013) notes that digital governance may be potentially assist Small Island Developing States (SIDS) in achieving higher levels of 'good governance'. Similarly, the United Nations e-Government Development Index pays special attention to SIDS and discusses the importance of digitalization for these countries (United Nations, 2018). It is proposed that digital governance has the potential to transform government, lead to more efficient practices, drive innovation, and facilitate interoperability and service development (Dunleavy et al., 2006; Torres, Pina, \& Royo, 2005). While digital governance is still a heavily debated topic, it will be understood here as a concept that "focuses on steering mechanisms in a certain political unit, emphasizing the interaction of State (First), Business (Second), and Society (Third Sector) players" (Drechsler, 2004) through digital means, such as Information and Communication Technologies (ICTs).

It is important to note that, while many works on digital governance believe that digitalization will lead to organizational or administrative transformation, this may be something of a myth (Norris, 2010; Bekkers \& Homburg, 2007). Digital governance is most often associated with external processes, that is to say, service delivery-often on the G2G (Government to Government), G2B (Government to Business), or G2C (Government to Citizen) level (Norris, 2010). The premise is that the introduction of ICTs allows for services to be delivered to citizens in a faster, more efficient (cheaper), and effective way, thereby improving quality of life for the service user. If services are delivered cheaper, bureaucracy may be able to shrink and save money. However, digital governance is expensive and labour intensive and brings with it many new challenges for government. Digital governance requires new digital infrastructure to be built and maintained, new services and tools to be developed, new bureaucrats with technical skills to be hired, and new cyber and digital security risks to be monitored and analysed.

Additionally, it is often the case that offline methods remain available during this period in case digital services become unavailable for technical reasons or due to the digital divide, with certain citizens unable to use or access new digital services (Helbig, Gil-Garcia, \& Ferro, 2005). As there are high costs associated with the initial states of digital governance, these efforts for the most part require a high uptake and number of users in order to be cost effective. This is interesting, given that there have hitherto been limited studies explicitly focusing on how the size of a state influences digitalization. While studies do exist that explore digital governance in small territories (Cullen \& Hassall, 2017; Kalvet, 2012; Li, Detenber, Lee, \& Chia, 2004), state size is often not explicitly included as a variable in analyses of the implementation or performance of digital governance initiatives. So, there is a situation in which bureaucracy and public administration within small territories have been associated with certain limiting factors, and digitalization has been proposed as a potential solution to overcome these limitations, yet there appears to be a research gap regarding how this process unfolds and how the context of smallness influences the digitalization process.

\section{Methodology}

The research in this paper is interpretive in nature, regarding "our knowledge of reality [as] a social construction" and seeing this knowledge as "incapable of being understood independently of the social actors" (Orlikowski \& Baroudi, 1991). The case study is among the most common 
qualitative interpretivist research methods. This can be differentiated from other basic qualitative studies in its focus on a single unit of analysis rather than a broad topic (Merriam \& Grenier, 2019). While there are many different case study approaches (see e.g. Eisenhardt, 1989; Yazan, 2015; Yin, 2013), the present research can be classified as a descriptive case study in which the goal is to create a "rich, thick description of the phenomenon under study" (Merriam, 1998; ctd. in Yazan, 2015). In this instance, the paper focuses on Talgildu Føroyar to provide a descriptive narrative of how the Faroe Islands has begun its digitalization journey.

This research relies heavily on semi-structured interviews but is also supported by participant observation, ethnographic evidence, and document review. During a three-week research field visit to the Faroe Islands in November 2018, 22 semi-structured interviews were conducted in-person with interviewees from academia, the public and private sectors, parliament, government agencies, and among other island citizens. The interviews started with key stakeholders, such as the project manager of Talgildu Føroyar, and additional interviewees were identified through snowballing and by reviewing internal Talgildu Føroyar documents that highlighted important stakeholders in the digitalization project. Additionally, one interview was carried out in February 2019 by e-mail with the Minister of Finance of the Faroe Islands. The questions asked during the semi-structured interviews focused on understanding: motivations for digitalization, feelings about the digitalization process so far, barriers faced during the digitalization process, and the legal and organizational environment that influenced the digitalization process (questions were altered to better fit each stakeholder's context). The interviews lasted between 30 and 60 minutes and were recorded in $80 \%$ of the cases (some participants did not wish to be recorded). Audio files were then transcribed and coded. The analysis and coding of the interviews followed conventional content analysis (Birks \& Mills, 2015; Hsieh \& Shannon, 2005), in which reoccurring themes and concepts are identified, and the developed findings are related back to initial codes and gathered evidence. Due to the small nature of the Faroe Islands and the close ties between partners, many interviewees wished to have certain comments fully anonymized and, as such, some quotes used in this research cannot be attributed. Overall, the interviews provided an overview of the different feelings, perceptions, and understandings of the digitalization process across many different interest groups.

During the three-week research field visit, the researcher was based in a government office and was allowed to observe and participate in meetings and discuss with government officials from a wide range of departments involved in digitalization, such as Talgildu Føroyar, Gjaldstovan, TAKS, and the Ministry of Finance. As a result of this direct access and participation, it was possible to gather additional ethnographic evidence in the form of participant observation. Documents analysed included slide shows and presentations from government organizations on the topic of digitalization, internal project documents focusing on implementation or planning of digitalization, official project reports, white papers, parliamentary rulings, newspaper reports, and web-based artefacts related to Faroese digitalization efforts. These documents were for the most part available in English. When the documents were only available in Faroese, they were translated or interpreted by native Faroese speakers.

As this research is epistemologically based on an interpretivist foundation, it is must be acknowledged that there could be alternative viewpoints or interpretations. Thus, it is important to ensure that it is clear how the interpretations that emerge from this research can be related back to the evidence and observations gathered. In order to ensure this higher level 
of internal validity and to support the interpretations made, data and evidence were triangulated. The interviews allowed new concepts to emerge for the study, which could then be validated against findings from the document analysis and participant observation. The interviews also supported the analysis of observations and concepts that emerged from the document analysis and participant observation. Due to the nature of a case study in which the researcher also engages in fieldwork and observation, there is the possibility of bias and of findings being presented in a subjective manner. However, by ensuring a high level of internal validity of the research design and by striving to present the findings in a neutral and objective manner, it is possible to minimize these risks.

\section{The case}

\section{Context}

Though this paper focuses primarily on the most recent digitalization effort in the Faroe Islands, a historical and contextual overview is needed in order to truly understand the case.

The Faroe Islands are strongly dependent on the fishing industry, however, as is often the case, relying on a single industry risks economic disaster if this industry declines (Hamilton, Colocousis, \& Johansen, 2004). This is exactly what happened in the early 1990s when the archipelago's human population rapidly declined from 48,000 in 1990 to 43,000 in 1996 due to a sharp drop in the fish population and a subsequent decline in the fishing sector: in the course of six years, the previous 20 years of population growth had been completely undone (Hamilton, Colocousis, \& Johansen, 2004). The crisis worsened when Danish banks devalued the homes on the Faroe Islands, essentially bankrupting a large majority of Faroese citizens. This, combined with what is now known as the 'Great Bank Affair' (Adler-Nissen, 2014), created a large rift between Faroese society and Denmark and has played a major role in influencing how the Faroese chose to develop as a territory and emboldened calls for independence from Denmark. After the economic crisis, the Danish financial sector once again hurt the Faroe Islands' economy when a decision was made to move all IT capacity and infrastructure back to Denmark from the Faroe Islands. Almost overnight, this caused great damage to Faroe Islands' entire ICT sector (Randall \& Berlina, 2019).

Politically, the Faroe Islands is a democratic SNIJ with a multi-party political system that identifies as Scandinavian and, as such, has similar democratic, cultural, and societal values as the Nordic countries. The Faroes, though small, have a vibrant and active democracy with an election turnout consistently over $90 \%$ (Hoff \& West, 2008). With regard to citizenship and democratic participation, the Faroese have among the highest rates of participation in Scandinavia when it comes to contact with politicians and officials, but they are less likely to engage in more outwardly focused types of participation, such as writing news reports or participating in boycotts (Hoff \& West, 2008). This is expected due to the small networked type of society that is present on the Faroe Islands. Elections for the Faroese parliament, Løgting, are intense, with seven parties competing for some 30,000 votes. The prime minister of the Løgting is able to appoint ministers to the seven Faroese ministries: Ministry of Finance; Ministry of Education, Research and Culture; Ministry of Fisheries; Ministry of Foreign Affairs and Trade; Ministry of Transport, Infrastructure and Labour; Ministry of Social Affairs; and Ministry of Health and the Interior. Each minister is assigned responsibilities by the Prime Minister and given control/put in charge of different public institutions. 
While policy creation and management of public institutions primarily happens at the national level, a large number of responsibilities have been devolved to the 29 municipalities that make up the Faroe Islands. Municipalities in the Faroe Islands are, for the most part, sparsely populated, with 24 of the 29 municipalities having populations below 2,000 (the largest municipality, Tórshavn, has a population of just above 20,000) (Faroe Islands Government, 2019). These municipalities have the power to tax residents, and this is shared with the national government (TAKS, 2019; Jósup Henriksen, Interview 2018). Additionally, every municipality is responsible for service delivery, such as services related to elderly care, schools, public transport, and waste (Útledingastovan, 2017). As municipalities are responsible for service delivery and some aspects of taxation, it is with this level of government that citizens will interact in a majority of situations.

\section{The beginning}

The story of Faroese digitalization has its roots in TAKS, an organization within the Ministry of Finance that is responsible for the collection of taxes and revenues as well as administering any other taxation legislation put in place by the Faroese parliament. In 1984, TAKS launched its new taxation system, which all but eliminated the need for citizens to file taxes manually. Employers send employee wages directly to a central wage system, the taxes due are automatically calculated and withdrawn, and then the net wages are sent directly to the bank and made available to the employee. At the end of the fiscal year, TAKS sends out a letter to each person stating how much they paid in tax, how much they earned, and if the information is correct, they does not need to do anything more. For this tax system to become feasible, a unique identifier was needed for every Faroese citizen, so, in 1984, the Faroese 'P-Number' was created and maintained by TAKS. The creation of the P-Number required a legal act passed by parliament and met with much resistance as the number was associated with the "mark of the devil" (Nicolai Balle, Interview 2018; Helena Højgaard, Interview 2018). In order to help pacify the resistance to the identifier, it was made confidential and requires explicit authorization from the citizen to use except where required by law (Jósup Henriksen, Interview 2018). Since 2000, the letter-based system utilized by TAKS has been replaced with an online environment, which was renewed again in 2015 and is known in Faroese as Borgaragluggin. Faroese citizens are able to access the online portal using a Faroese ID solution known as MyKey, and from here they verify whether the tax information was gathered successfully. In the rare cases in which extra information is needed, the citizen is also able to provide it via the portal. Businesses also have access to an online environment where VAT, customs, end of year reporting, etc. can be done via electronic means. This has been available in some form since 2004 and has improved over the successive years.

Though TAKS is the primary example of digitalization, it is not the only one. For example, Føroya Tele, the Faroese telecoms provider, has managed to create one of the most connected societies in the world by providing a broadband penetration rate of $100 \%$ and $98 \%$ geographical coverage, thus creating a truly networked society on a "small collection of rocks in the Atlantic" (Jan Ziskasen, Interview 2018). At the national level, billing, invoices, accounting, and handling of national accounts is handled in a digital manner by the Ministry of Finance organization known as Gjaldstovan (Gjaldstovan, 2019). Additionally, since 2011, the Faroese national health system has been digitalized with the introduction of a e-Health record platform, which allows doctors around the Faroe Islands to access a patient's healthcare 
records. Pharmacies are also connected, allowing for the usage of digital/electronic prescriptions (Jóanis Køtlum, Interview 2018). At the municipal level, only the two largest municipalities, Tórshavn and Klaksvik, have made progress when it comes to e-Services. However, these advancements are quite small in scope and are essentially limited to filling out forms online, and only in a few situations. For example, the Municipality of Tórshavn allows residents to sign up for kindergarten places online via an e-Form from its municipal webpage rather than in person. The Municipality of Klaksvik offers 22 different services/forms that can be filled out on its municipal service portal, located at: https://www.klaksvik.fo/sjalvgreidsla.

\section{Talgildu Foroyar}

Talgildu Føroyar is responsible for digitalization in the Faroe Islands. While the project is coordinated at the federal level, it relies heavily on involvement and investment from a wide variety of stakeholders, such as municipalities, banks, telecommunications companies, ICT development companies, other private sector stakeholders, and citizens. This is especially evident in how the project is funded. Talgildu Føroyar was given a budget of 150 million Danish kroner (DKK), with 60\% coming from parliament, 17\% coming from municipalities, and $23 \%$ coming from private external stakeholders (Balle, 2018). In addition to providing funding, there is also direct involvement of a wide variety of stakeholders in monitoring the progress of digitalization, with members of the IT industry, municipalities, and private sponsors serving as part of the program steering group (Balle, 2018; Talgildu Føroyar, 2015). Due to the wide variety of involved stakeholders and parties, it follows that digitalization can provide some sort of benefit for all. In order to accomplish this, Talgildu Føroyar aims to construct the new Faroese digital society based on four primary pillars shown in Figure 2: a citizen service portal, electronic identity (eID), interoperability, and basic data (Talgildu Føroyar, 2015; Kristina Háfoss, Interview 2019).

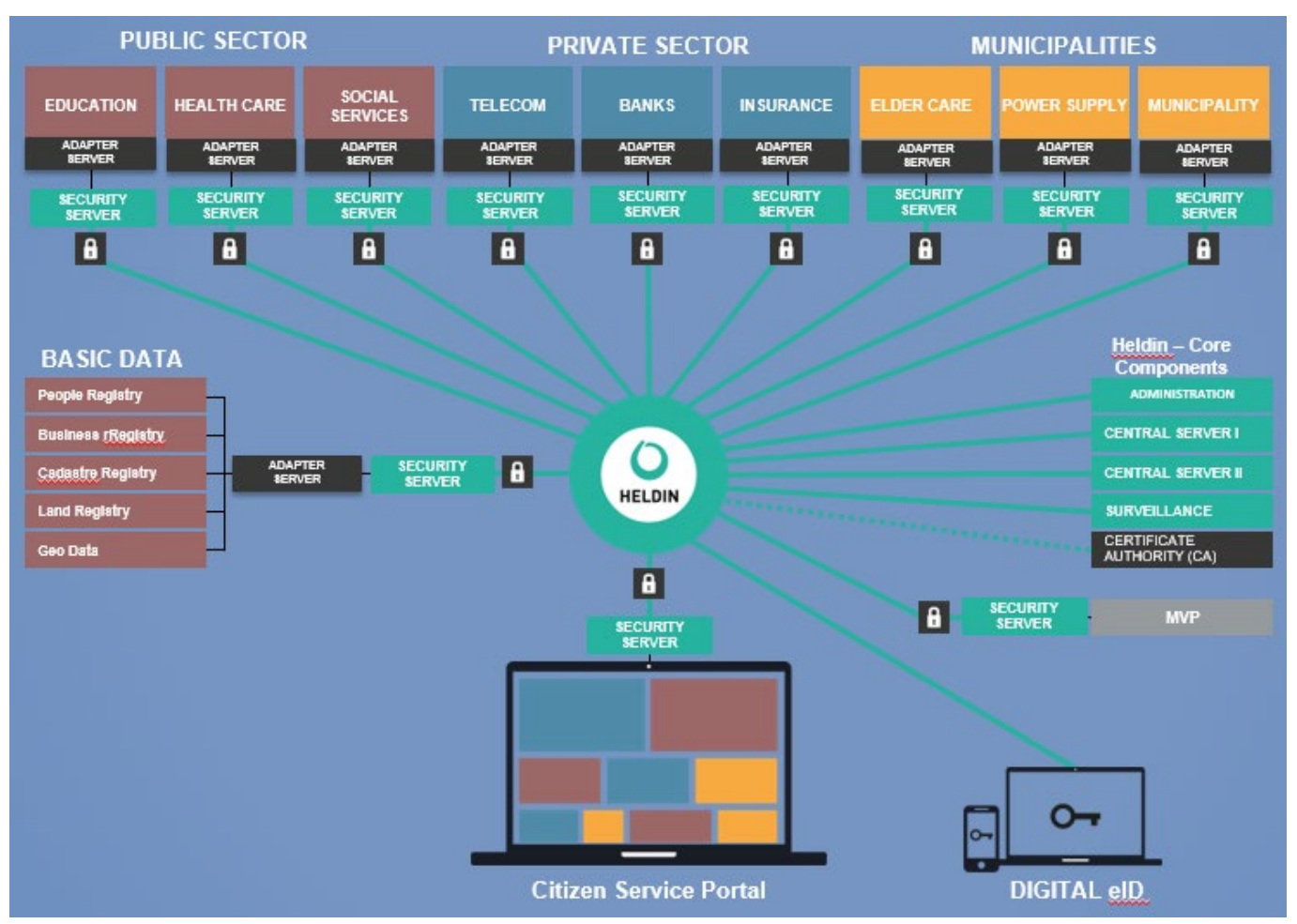

Figure 2: Faroe Islands digital governance. Source: Balle, 2018. 


\section{Citizen Service Portal}

The citizen portal aims to provide citizens access to their information that is currently held in different government databases and, additionally, to provide a 'one-stop shop' for e-services. While the idea of a 'one-stop shop' for e-services is not new, Talgildu Føroyar mandated in its procurement that the portal must be built using a 'low-code' system. Low-code development platforms allow for applications to be developed through a graphical user interface and tend to allow for faster development (Dunn, 2018). That being said, there are trade-offs. Some of those involved with the implementation and development of the citizen portal disagreed with Talgildu Føroyar on the importance of the 'low-code' system and highlighted that they felt constrained or limited in what they were able to do, were faced with a lack of customization and choice, experienced issues with interoperability, and were inhibited their ability to pivot and adapt to changes in the future. Talgildu Føroyar have also aimed to make the user interface and user experience a priority from the beginning and have hired an expert as part of the core team. Though the portal is in development, there are not yet many e-services available, and, as such, the initial usage of the portal is likely to be limited to simply viewing one's information (Ásla Rasmussen, Interview 2018). Currently, the first data to be made available on the portal is information that exists in the population registry, a citizen's religious affiliation, and genealogy (Ásla Rasmussen, Interview 2018).

\section{Electronic Identity (eID)}

Arguably, one of the most important parts of any digitalization effort is the existence and usage of a digital identity (European Commission, 2019; European Union, 2017). The digital identity allows for a service provider to use unique identification information to know that the service user is who they say they are. In the Faroe Islands, this identifier is known as the P-number and is a confidential number only to be used by government agencies and those who have received explicit consent from the citizen. Due to the limitations associated with $\mathrm{P}$-number usage, other alternatives have been used for identification in the Faroes for different use cases. For example, a solution known as MyKey was developed and used for authentication and identification with TAKS online solutions, but this is now outdated in terms of security (Meyerhoff Nielsen, 2016). A Danish solution, NemID, was used by Danish banks and had a wide uptake: at the beginning of the digitalization process, it was debated whether to create a new identity system or simply to adopt NemID from Denmark (Rolf Olsen, Interview 2018; Randall \& Berlina, 2019). However, due to historical and political grievances associated with the Danish banks, the debate surrounding digital identity became tied to the debate surrounding Faroese independence. Thus, it was decided that any new digital identity solution used should be owned and built by Faroese companies to demonstrate the capacity of the Faroese IT sector.

The new Faroese digital identity solution is ambitious; unlike in many other territories, there is no ID card, and a mobile phone application is to be used instead. Talgildu Føroyar wanted to be future oriented and stated that it could either copy the "outdated Estonian ID card-based solution, or develop something on their own more adapted for their society" (Anonymous, Interview 2018). Due to the high level of mobile phone penetration and almost universal access to data and internet (1.2 cell phones per person and $92 \%$ of households with internet available (Randall \& Berlina, 2019)), a mobile based solution is more feasible than in other territories (Talgildu Føroyar, 2016). However, it is also acknowledged that not every 
person can be expected to use a mobile phone for identification purposes, and a crypto USB solution is also offered as an alternative. The new digital identity will be eIDAS compliant and allow citizens to access all online e-services. Even though the proposed solution is quite innovative, there are also some weaknesses that must be addressed. For example, this solution is only viable for online identification and cannot be used, for example, to identify oneself when picking up a prescription from the pharmacy or as a substitute for a driver's license. Legally speaking, there is currently an ongoing debate about how to use and adopt the digital identity and digital signatures into law. While there will be a requirement for all government service providers to use the new eID solution, and the eID will be used as the standard for digital signatures in the Faroe Islands, it is unclear whether it will be possible to mandate private sector companies to use the new eID. Though it is debated whether the private sector can be forced to use the new solutions, what is not debated is the fact that usage of the new eID in the private sector is key to the identity scheme's success; if citizens do not use the eID, then it will fail, and the digitalization effort will be dramatically hindered (Jan Ziskasen, Interview 2018; Ólavur Ellefsen, Interview 2018).

\section{Interoperability}

As the Faroe Islands becomes increasingly digitalized, there needs to be a way for data to move between organizations, agencies, and service providers in a fast and efficient manner. In the Faroe Islands, the Estonian interoperability platform X-Road has been adopted, implemented, and renamed in Faroese as Heldin. This solution allows data to move between service providers in a fast, secure, and efficient manner. Services in the Faroe Islands already communicate with each other, but this is often done in an unsecure or inefficient manner (Ann Damgaard, Interview 2018; Randall \& Berlina, 2019). The older systems in place, such as those run by TAKS, communicate directly with each other via REST interfaces and other custom-built integrations. This leads to a situation in which data is not always up-to-date and also creates multiple potential points of failure. However, this will change as these services will be required to be brought onto and become compatible with Heldin. Bringing old systems onto Heldin will require a large investment, both financially and in terms of time, due to a high level of technical complexity.

To illustrate this, the example of the Faroese Person Registry, originally known as LFY, is provided and shown in Figure 3. This registry was originally built and maintained by TAKS, but a change in the law created a new person registry, FOLK, under the responsibility of the Ministry of Environment. However, as so many systems had been directly communicating and integrated into the original LFY registry, it was seen as too complex to move all the integrations to the FOLK registry. Both databases now exist in tandem, and TAKS simply copies data directly from the FOLK registry to its LFY registry every night in an attempt to stay up to date. 


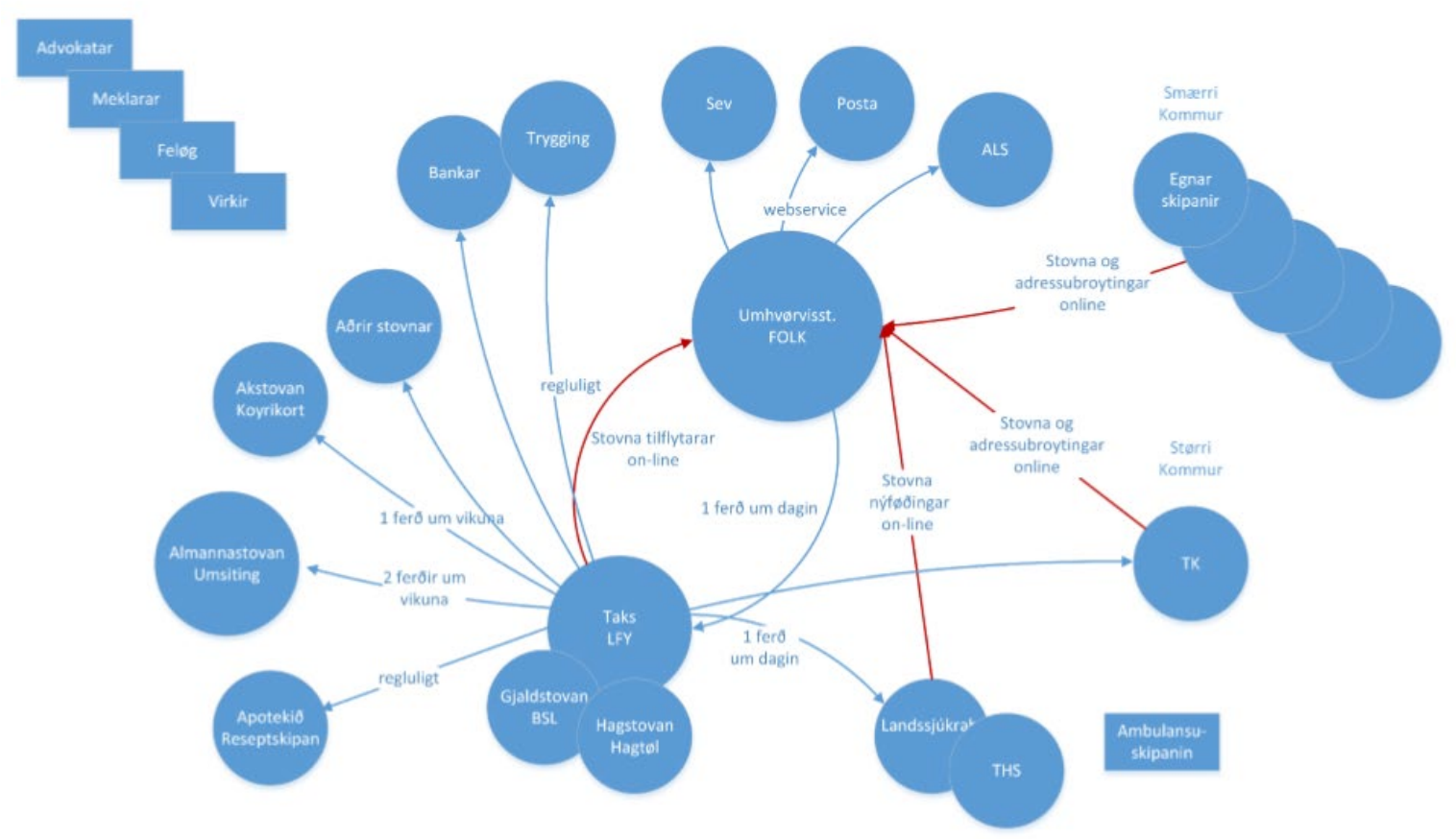

Figure 3: Faroe Islands current integrations. Source: Hanssen, 2017.

The interoperability solution helps combat these sorts of situations and allows for information to be held and accessed in one place. Heldin has a standard communication protocol, clear metadata, and clearly defined services (Hanssen, 2017). This ensures that data held by one organization can be easily accessed by another organization. Due to the strict metadata requirements and service descriptions, it should hypothetically facilitate an increase in data quality. However, in practice, some interviewees noted that the systems often do not work as described, and this has led to arguments between public and private service. An additional complaint that has arisen around Heldin is due to the fact that many of the systems currently in place have been developed and built by private sector Faroese IT companies over the past few decades, and they have a vested interest in keeping them in place. Thus, at least initially, there was pushback from Faroese IT companies, as this is one instance in which the digitalization project was more of a hindrance than a benefit, potentially limiting a primary area of business. However, the digitalization could also increase competitiveness by forcing competing IT companies to build services compliant and compatible with the same interoperability platform (Ulla Joensen, Interview 2018; Ann Damgaard, Interview 2018). As the uptake of the interoperability platform grows, it should allow for a new ecosystem to emerge that is conducive to the quick movement of data between service providers and service users, more secure movement of data, and more efficient implementation and design of services. At the time of writing, Heldin has been adopted by 34 institutions, 61 information systems, and 37 services (Talgildu Føroyar, 2019). 


\section{Basic data}

The final component of the Faroese digital governance initiative is basic data. During the strategic study, Talgildu Føroyar identified five main sources of data that it viewed as critical for the implementation of any digital government effort. These data sources were: a population registry, business registry, cadastre registry, land registry, and geospatial data (Heini Hátún, Interview 2018). Though many of these sources of data already existed, some needed to be established. For example, there is no business registry within the Faroe Islands. The cadastre, land registry, and geospatial data all exist and are held by the Ministry of Environment. While most of the geospatial data is of high quality (Umhvørvisstovan, 2019; Petur Nielsen, Interview 2018) and now freely available, the land and cadastre registry may not be up to date, as, due to the small size of the Faroes, if something changes, everyone already knows about it,, and there is no need to update the electronic registry (Leif Abrahamsen, Interview 2018). This would cause issues in a truly digital society as there is an assumption that all information held within registries should be up-to-date and easily accessible. As a result, effort has been devoted to improving and updating these datasets. The one aspect of basic data that does not yet exist in the Faroe Islands is the business registry. As many of the datasets required for basic data already exist within the Ministry of Environment, the original idea was to base the business registry within the Ministry of Environment as well (Petur Nielsen, Interview 2018). However, the business registry has little to do with its dayto-day operations. A home for this dataset is now being sought, and debates about the ownership of this data continue.

\section{Analysis}

Though the digitalization process is still in its initial stages, and the architecture and infrastructures are still being and developed, the Faroe Islands does appear to be motivated in its mission of enabling digital governance. The Minister of Finance noted that "digitalization is happening whether we want it or not. The question is, whether we want to be in control of the development or not. We have chosen not to let the development be random" (Kristina Háfoss, Interview 2019). The Faroes are able to begin their digitalization efforts and try to drive the process and make sure it does not happen in a random manner; however, it is also important to acknowledge and embrace the context of being a small state and take into account and plan for the factors that may influence the digitalization process.

It is clear that the Faroe Islands have committed to developing its digital governance capacities, but as one interviewee noted, "If I build a house, I can see my house. If we dig a tunnel, we can see the tunnel. If I build a boat, I can see my boat. But with digitalization, what can I see? How can I know what it does?" (Jacob Vestegaard, Interview 2018). Thus, the questions remain: Why has the Faroe Islands made digital governance as a strategic priority? How can it be understood? And what exactly will the Faroe Islands get in return for its digital governance investments? Depending on who one talks to, the answers will vary. For example, the Minister of Finance, Kristina Háfoss, stated that digitalization will change how things are done and should lead to increased quality, more sustainable solutions, and better connections between nations and people (Kristina Háfoss, Interview 2019). Similarly, Talgildu Føroyar argues that this digitalization will lead to transformation. As a result of this transformation: 
There is no doubt that the effect of the Digital Strategy will be a more efficient and flexible public sector, which will be more cost-effective [...] The purpose of digitalization must always be to ensure the easiest, safest, and most reasonable solution. This entails that administrative customs, guidelines, processes, and structures must be re-evaluated, and if necessary adjusted, when services are digitalized (Talgildu Føroyar, 2015).

In contrast, some interviewees from the private sector viewed these changes as primarily positive but were hesitant to believe any real change would follow. Some government officials also argued against this idea, noting that digitalization is something that is occurring due to external environmental pressure, rather than internal demand (Jacob Vestegaard, Interview 2018, Leif Abrahamsen, Interview 2018).

What is clear is that while everyone seems to agree digitalization is happening, the reasons for it and the expected benefits are still widely debated by stakeholders within the Faroe Islands. Thus, this discussion section aims to bring some clarity to this debate by drawing upon the results of the conducted case study and exploring the four most common themes that emerged relating to $w h y$ the Faroe Islands should digitalize and what benefits stakeholders expected as a result of digitalization. These four primary themes were: cost effectiveness and efficiency, demographics, economics, and independence. To better understand each of the identified themes associated with digitalization, each one will be examined individually in the following subsections.

\section{Cost effectiveness and efficiency}

While in larger territories, digital governance may lead to cost savings and increased efficiency, in the Faroe Islands, this benefit may not occur. TAKS was the first citizen-facing organization to launch e-services with its citizen and business online tax portals. TAKS' experience seems to suggest that digitalization is not necessarily a quick fix. While it is true that less paper is now used, the tax returns go faster, and citizens and TAKS employees are generally happier, the workload has not disappeared; it has simply shifted, with more staff being routed to customer support (Diana Gilstón, Interview 2018; Helena Højgaard, Interview 2018). While e-services have enabled the removal of lower-tier work by putting the services online, there are now more opportunities for people to have problems with tax papers, which has led to increased phone calls and customer interaction (Diana Gilstón, Interview 2018). This was surprising as "this was too many calls, especially when looking at the energy and investment needed to uplift our self-service possibilities" (Diana Gilstón, Interview 2018). Interestingly, at the same time, TAKS closed the in-person customer support opportunities at all its offices except for the main office in Tórshavn. This was done to ensure that citizens and businesses received a consistent level of service and accurate information, which was only possible by consolidating the customer support offices. Thus, while digitalization is meant to transform the service delivery process and help reduce administrative burdens, what has happened instead is the reinforcement of an organization that can now be associated with one physical building, demonstrating that digitalization is less about doing something new than about doing the same thing in a different way; bureaucracy is far from disappearing (Drechsler, 2019). 
Outside of TAKS, the idea that digital governance will save money was also classified as a myth by the current head of Gjaldstovan (Leif Abrahamsen), the organization responsible for Faroese IT and accounting. While discussing the idea of digital governance, Leif noted that many services are only used two or three times a year and that, from a cost-based standpoint, digitalization in the Faroes will never be cost effective. He noted that, with the current digital systems already in place, human resources are strained, with people holding responsibility for multiple systems, whereas in larger territories, one person would be responsible for only one system (Leif Abrahamsen, Interview 2018). Similarly, within TAKS, some of the departments, such as the one responsible for citizen taxation, have a majority of the staff approaching the age of retirement, with many staff members expressing discomfort working with the newest technologies (Johan Heinesen, Interview 2018). If digitalization is to progress to a level at which it is widely used across the Faroe Islands, it requires buy-in from stakeholders in both the public and private sectors. In order for this to happen, investments in the creation of new IT systems are needed, and there will be an increased need for IT experts who can successfully work with and manage these systems.

To date, a majority of the IT experts in the Faroe Islands are either self-trained or received education outside the Faroe Islands. In order to try to change this, the University of the Faroe Islands launched a bachelor's program in software engineering in 2010 (Fróðskaparsetur Føroya, 2019). However, this program only admits students every two years (meaning there have only been five intakes of students at the time of writing), and, according to some private sector actors, the quality of education is generally low, with the curriculum inadequately preparing students for working with current or future IT systems in the Faroe Islands (Anonymous, Interview 2018). In addition to these costs, the Faroe Islands must cope with having a local language spoken by only around 70,000 people. This creates an additional cost in that the Faroese must devote additional resources to bringing their language and culture into the digital sphere, which further increases expenditure.

\section{Demographics}

With only a small number of people living in the Faroe Islands, there is constant concern about how to maintain or increase the size of the population. The Faroese are connected digitally to the rest of the world but are geographically disconnected. This leads many Faroese youth to travel to Denmark (where there are more opportunities and close cultural connections) or to other countries to pursue opportunities not available at home (Meyerhoff Nielsen, 2016). The Faroe Islands hopes to use its digital governance program to address this group and create new opportunities at home to bring the diaspora back (Helena Højgaard, Interview 2018; Talgildu Føroyar, 2015). Those who do not remain in the Faroe Islands will still be able to remain connected with their government back home via the new eID and service portal. Wherever you are in the world, it is hoped that you can remain connected to the Faroe Islands. Additionally, it has been argued that those who leave the Faroe Islands, especially to Denmark (which constantly tops digital government indices as one of the top performers in the world (United Nations, 2018)), acquire a level of expectation when it comes to digital services: if these things are available somewhere else, they should also be available in the Faroe Islands (Leif Abrahamsen, Interview 2018; Nicolai Balle, Interview 2018). So, digitalization becomes less about being innovative and more about catching up and matching citizen expectations, which should hopefully allow the Faroe Islands to remain competitive and comfortable as a place for 
people to stay and live. In addition to attracting Faroese abroad back home, it has been claimed that investment in digital governance should help drive immigration to the Faroe Islands and increase the flow of foreigners coming to stay and work (Talgildu Føroyar, 2015; Kristina Háfoss, Interview 2019). This attractiveness should come primarily from growth in the IT sector, with private sector companies looking abroad for the much-needed IT talent. Additionally, the City of Tórshavn's IT department manager also has ambitions to transform Tórshavn into the "startup capital of the North Atlantic" (Lars Black, Interview 2018), which would allow for a startup-friendly ecosystem and encourage foreign talent to come to the capital city.

It seems there is an effort to intertwine digital governance with the core Faroese identity, with Kristina Háfoss arguing that "the digital world and the digital reality is becoming an increasingly important part of the Faroe Islands society and identity" (Kristina Háfoss, Interview 2019). Others also noted the importance of digital technologies for the Faroese livelihood, as it is the best way to remain connected with the outside world. In fact, the Faroe Islands has shown its savvy when it comes to digital technologies and social media by organizing digital campaigns that went viral, such as the 'sheep view' campaign, which brought Google Maps to the Faroe Islands (Durita, 2016) and the crowd sourced 'Faroe Islands Translate' campaign (Visit Faroe Islands, 2017). These campaigns both show and help support the argument that the Faroe Islands has begun to embrace the 'digital' as part of its culture and identity. This is interesting as, if digitalization becomes part of the Faroese culture, people who emigrate overseas can still generate substantial benefit by playing the role of ambassadors even if they do not move back to the Faroe Islands simply by sharing or talking about their culture and digital governance efforts in their home state.

\section{Economy}

The Faroe Islands, as is the case with many small territories, are strongly dependent on a single industry, in this case, fishing. It is hoped that digital governance will help remove the Faroese reliance on this industry by fostering the development of the IT sector, which had previously been crippled by Danish banks removing their IT infrastructure (Meyerhoff Nielsen, 2016; Randall \& Berlina, 2019). In an effort to ensure that investments into digital governance directly benefited the Faroese economy, procurement requirements stated that all solutions must be built by Faroese IT companies, and every effort should be made to outsource the development (this is only possible as the Faroe Islands are not bound by EU procurement requirements) (Randall \& Berlina, 2019; Talgildu Føroyar, 2015). However, this comes with its own disadvantages, for although the IT capacity of the private sector is quite high and continues to improve, the bureaucracy's internal IT capacity suffers as there is no internal development related to the solutions. This is a strategic decision that elevates the importance of the private sector in the governance of the Faroe Islands as its competence will become a strategic requirement that may remain lacking in the bureaucracy.

The digitalization project represents the largest IT project in the history of the Faroe Islands and is driving the growth and creation of new jobs in this industry (Kristina Háfoss, Interview 2019). The importance of digitalization for this industry is also clear to the private sector, which has provided 23\% of the total digital governance budget (DKK 34 million over the course of the project) (Balle, 2018). When it comes to the development of the different infrastructural components of the Faroese digital governance program, there are four main companies: Formula, Electron, Klintra, and Føroya Tele (Helena Højgaard, Interview 2018; 
Ólavur Ellefsen, Interview 2018; Gert Joenson, Interview 2018). During interviews with representatives from these companies, the response was largely positive, with every interviewee hoping that the project succeeded. One interviewee discussed how the new project has allowed companies to talk together and cooperate in ways that had not happened before (Ulla Joensen, Interview 2018). The CEO of Føroya Tele noted that it hopes to play a key role in the digital governance process, is driven by a desire to be number one in the world, and that this project will help the company achieve this goal (Jan Ziskasen, Interview 2018). However, there were some complaints related to restrictive procurement and fear that this initiative, while providing funding for the companies, was stifling their innovative potential. Additionally, some companies that had helped build the currently in-place interoperability solutions felt that the newly required Heldin platform did not work well and, if given the choice, would prefer to stick with their self-built solutions.

\section{Independence}

The final theme that emerged during the research was the importance of the Faroe Islands' independence and geopolitical relations with Denmark as a driving factor for digitalization. There seems to be a direct relationship between the Faroe Islands' push for digitalization and the SNIJ's desire for independence. The historical context and recent controversies involving Denmark affected Talgildu Føroyar's technological procurement choices, with all solutions needing to be created in the Faroe Islands rather than adopted from Denmark. The same held for the political desire to digitalize: there was a feeling of, 'If Denmark can do it, so can we' (Anonymous, Interview 2018). It should also be noted that this drive for independence, especially when it comes to digitalization, may actually hamper Faroese development efforts. For example, as it stands, both Denmark and the Faroe Islands use the same e-health system, and the Faroe Islands are heavily reliant on Denmark for healthcare in more extreme cases and illnesses; however, these systems are not connected, which causes difficulty inn moving and accessing information about patients (Jóanis Køtlum, Interview 2018). This causes a situation in which the Faroe Islands is technically able to digitalize on its own, yet there is still a need to remain digitally connected and interoperable with Denmark. Thus, in the future, attention will need to be paid to the debate between digital autonomy and digital interoperability and the effect this has on independence and sovereignty.

When discussing the notion of independence and digitalization with the Minister of Finance, she noted that Faroese digital society must be "built on our values and on the foundation of the Faroese people and our society. This is our historic opportunity to create our own digital society and nation. Therefore, we have chosen not to be part of, or copy, the Danish digital solutions" (Kristina Háfoss, Interview 2019). But while this is currently the government position, it could change in the future if a pro-Denmark coalition were to gain power in the Faroe Islands. However, at this moment in time, and at the initiation of the digitalization project, it is clear that the process has at least in part been about further distancing the Faroe Islands from Denmark.

While there has historically been a tendency to adopt solutions that have already been trialled and demonstrated to be successful in Denmark, the current efforts' strong focus on outsourcing and looking to other digital governance leaders, such as Estonia, has led to the development of new relationships and networks. These networks help when it comes to building institutional and technological capacity through a knowledge-transfer process. They 
also help frame the Faroe Islands in the international arena as a potential future leader in digitalization leader. Overall, the idea of rallying behind a digital governance program to create new 'digital institutions' and further separate the Faroe Islands from Denmark is interesting and could pave the way for many other areas in which independence is desired.

\section{Conclusion}

In the Faroe Islands, there is a desire to mimic the success and achieve the benefits that other countries and territories have experienced with digitalization. However, these desires are bound within the Faroe Islands' context as a small state and must overcome typical small state issues, such as lack of access to skilled experts, small population, high cost of governance, and lack of access to local innovative markets. In order to better understand the digitalization process of a small state and how it is affected by its context, this paper presented the initial results of an interpretive case study that aimed to provide a descriptive narrative of how the Faroe Islands have engaged in the digitalization process. The research focused primarily on one temporary, project-based organization known as Talgildu Føroyar and, by conducting fieldwork; engaging with stakeholders; conducting semi-structured interviews; and paying close attention to the different motivations, values, and beliefs, it became possible to better interpret and understand the digitalization process. Thus, the main contributions of this paper is a new description and understanding of the digitalization of the Faroe Islands as well as identification of key contextual factors that influence this process and key beliefs about digitalization that have affected the current digitalization trajectory.

With regard to the contextual issues affecting the digitalization process, it is argued that digitalization is generally more difficult, less cost effective, and less likely to alter the size of the bureaucracy in smaller territories than in larger territories.

Interestingly, many of the interviewees came out strongly against the idea that digitalization was easier in a small territory, noting that due to the Faroe Islands' small size, any sort of change was in fact harder than in larger territories (e.g. Leif Abrahamsen, Interview 2018; Jacob Vestegaard, Interview 2018). This was primarily due to the networked and informal relationships that are prevalent in small societies, which requires a long grassroots effort to convince the whole of society of the benefits of digital governance. It has also been found that, while digital governance may well make sense from a cost standpoint in larger territories (Asgarkhani, 2005; Yang \& Rho, 2007), this is simply not the case in the Faroe Islands. The costs of digital governance in terms of new technologies, infrastructure, development, and maintenance cannot be spread across a large population and thus remain disproportionately high. Additionally, as digital governance requires up-to-date infrastructure to function properly, services that are rarely used and function effectively and efficiently in their current form must be redesigned and brought into the digital age. In addition to the high costs, it also appears to be a myth that digitalization leads to a decreased bureaucracy or decreased government-citizen interaction. This issue, while manageable within a single organization, does not scale well due to the Faroe Islands' small population and lack of access to the necessary skilled experts. In order to counter this, explicit steps should be taken to increase the availability of knowledgeable IT experts in the Faroese public sphere.

In addition to the contextual factors that influenced digitalization in the Faroe Islands, it was possible to identify four key motifs that affected stakeholder beliefs and perceptions 
concerning digitalization: cost effectiveness and efficiency, demographics, economics, and independence. There was a common belief that digitalization would lead to a more effective, efficient, and cheaper bureaucracy, though as mentioned above, this is unlikely to occur. Concerning demographics, it was often said that digitalization of the Faroe Islands is not optional but is something that is a necessity to ensure the future of the Faroese people and attract people to come (back) to the Faroe Islands. However, as the digitalization project is not yet complete, it is not yet possible to measure the effect this will have on the demographics. With regard to economics, it is widely believed and hoped that digitalization and the requirement to use Faroese IT competencies will revitalize the IT sector. Based on interviews with private sector actors, these benefits already seem to be appearing. Finally, it was overwhelming stated that the digitalization of the Faroe Islands utilizing Faroese solutions helps advance the cause of independence from Denmark.

While this paper does provide an initial description and interpretations of digitalization in a small island territory, future research could be conducted to ascertain whether the same drivers and factors are also present in digitalization efforts in other small island territories. This research seeks to represent all stakeholder groups in the interviews, but it is highly biased towards the private and public sectors. Thus, future research should also focus on better understanding citizen perspectives on digitalization of the Faroe Islands and comparing whether these match the factors identified in this paper. Finally, as the digitalization process is still ongoing, future research should be conducted to identify and compare the actual effects of digitalization on the governance of the Faroe Islands.

\section{Funding}

This work was supported by ASTRA “TTÜ arenguprogramm aastateks 2016-2022” Doctoral School in Economics and Innovation Project code: 2014-2020.4.01.16-0032, the European Commission (OpenGovIntelligence H2020 grant 693849), and TalTech Digital Governance Competency Center (SS483).

\section{Acknowledgements}

Gratitude is extended to all interviewees who spent the time to discuss their feelings about digitalization in the Faroe Islands. Special thanks must be extended to Nicolai Balle, Helena Højgaard, and the entire team at Albert Hall. Tiina Randma-Liiv, Külli Sarapuu, and Wolfgang Drechsler helped to make this research possible by sharing their knowledge and expertise on public administration and small territories. Additionally, thank you to the editor-in-chief and the reviewers who provided necessary constructive feedback to improve the quality of the paper.

\section{References}

Adler-Nissen, R. (2014). The Faroe Islands: Independence dreams, globalist separatism and the Europeanization of postcolonial home rule. Cooperation and Conflict, 49(1), 55-79. https://doi.org/10.1177/0010836713514150

Asgarkhani, M. (2005). Digital government and its effectiveness in public management reform. Public Management Review, 7(3), 465-487. https://doi.org/10.1080/14719030500181227 
Awan, O. (2013). e-Governance in Small States. In A. Ming, O. Awan, \& N. Somani (eds.). e-Governance in small states (pp. 25-41). London: Commonwealth Secretariat. https://doi.org/10.14217/9781848591585-6-en

Baker, R. (1992). Scale and administrative performance: The governance of small states and microstates. In B. Randall (ed.). Public administration in small and island states (pp. 5-26). West Hartford: Kumarian. https://doi.org/10.1002/pad.4230130215

Baldacchino, G., \& Milne, D. (2006). Exploring sub-national island jurisdictions: An editorial introduction. The Round Table, 95(386), 487-502. https://doi.org/10.1080/00358530600929735

Balle, N. (2018). The Faroese journey towards a digital society and the role of Heldin. Tórshavn: Talgildu Føroyar.

Bekkers, V., \& Homburg, V. (2007). The myths of e-government: Looking beyond the assumptions of a new and better government. The Information Society, 23(5), 373-382. https://doi.org/10.1080/01972240701572913

Birks, M., \& Mills, J. (eds.). (2015). Grounded theory: A practical guide. (2 $2^{\text {nd }}$ ed.). New York: Sage.

Bray, M. (1991). Education in small states: Growth of interest and emergence of a theory. Prospects, 21(4), 503-516.

Cullen, R., \& Hassall, G. (eds.). (2017). Achieving sustainable e-government in Pacific Island states. New York: Springer.

Drechsler, W. (2018). Pathfinder: e-Estonia as the $\beta$-version. JeDEM-eJournal of eDemocracy and Open Government, 10(2), 1-22. https://doi.org/10.29379/jedem.v10i2.513

Drechsler, W. (2004). Governance, good governance, and government: The case for Estonian administrative capacity. TRAMES, 8(4), 388-396.

Dunleavy, P., Margetts, H., Bastow, S., \& Tinkler, J. (2006). New Public Management is dead: Long live digital-era governance. Journal of Public Administration Research and Theory, 16(3), 467-494. https://doi.org/10.1093/jopart/mui057

Dunn, B. (2018). Low-code could change much more than just IT, according to Exec. InformationAge. Retrieved from https://www.information-age.com/low-code-it-123477572/

Durita (2016). Sheepview 360. Retrieved from https://visitfaroeislands.com/sheepview360/

Eisenhardt, K. M. (1989). Building theories from case study research. Academy of Management Review, 14(4), 532-550. https://doi.org/10.5465/amr.1989.4308385

European Commission (2019). Trust services and electronic identification (eID). Retrieved from https://ec.europa.eu/digital-single-market/en/policies/trust-services-and-eidentification

European Union (2017). Tallinn Declaration on eGovernment at the ministerial meeting during Estonian Presidency of the Council of the EU on 6 October 2017. Tallinn. Retrieved from https://ec.europa.eu/digital-single-market/en/news/ministerial-declarationegovernment-tallinn-declaration

Faroe Islands Government (2019). People of the Faroe Islands: Faroe Islands population. Retrieved from https://www.faroeislands.fo/people-society/people-of-the-faroe-islands/population/

Fróðskaparsetur Føroya (2019). B.Sc. í KT-verkfrøði. Retrieved from https://www.setur.fo/fo/utbugving/bachelor/kt-verkfrodi/

Gjaldstovan (2019). Gjaldstovan: About us. Retrieved from https://gjaldstovan.fo/Gjaldstovan/vit/ 
Government of the Faroe Islands. (2019). The Constitutional Status of the Faroe Islands. Retrieved from https://www.government.fo/en/foreign-relations/constitutional-status/

Grydehøj, A. (2018). Decolonising the economy in micropolities: rents, government spending and infrastructure development in Kalaallit Nunaat (Greenland). Small States $\mathcal{E}$ Territories, 1(1), 69-94.

Hamilton, L. C., Colocousis, C. R., Johansen, S. T. F. (2004). Migration from resource depletion: The case of the Faroe Islands. Society \& Natural Resources, 17(5), 443-453. https://doi.org/10.1080/08941920490430232

Hanssen, L. (2017). Heldin. Retrieved from https://d3pnpprk515r42.cloudfront.net/media/1716/2017-06-07-heldin-framløg-áverkstovu-um-ger-av-vevtænastur-lilly.pdf

Helbig, N., Gil-Garcia, J. R., \& Ferro, E. (2005). Understanding the complexity of electronic government: Implications from the digital divide literature. Government Information Quarterly, 26, 1-11. https://doi.org/10.1016/j.giq.2008.05.004

Hoff, J., \& Fríða West, H. (2008). Citizenship in the Faroe Islands: Participant, parochial or colonial? Scandinavian Political Studies, 31(3), 311-332. https://doi.org/10.1111/j.14679477.2008.00208.x

Hsieh, H. F., \& Shannon, S. E. (2005). Three approaches to qualitative content analysis. Qualitative Health Research, 15(9), 1277-1288. https://doi.org/10.1177/1049732305276687

Kalvet, T. (2012). Innovation: A factor explaining e-government success in Estonia. Electronic Government, 9(2), 142-157. https://doi.org/10.1504/eg.2012.046266

Kattel, R., Randma-Liiv, T., \& Kalvet, T. (2011). Small states, innovation and administrative capacity. In V. Bekkers, J. Edelenbos, \& B. Steijn (eds.). Innovation in the Public Sector (pp. 61-81). London: Palgrave Macmillan. https://doi.org/10.1057/9780230307520 4

Li, H., Detenber, B., Lee, W. P., \& Chia, S. (2004). E-Government in Singapore: Demographics, usage patterns, and perceptions. Journal of E-Government, 1(3), 29-54.

Merriam, S. B., \& Grenier, R. S. (2019). Qualitative research in practice examples for discussion and analysis. Hoboken: John Wiley \& Sons.

Merriam, S. B. (1998). Qualitative research and case study applications in education. San Francisco: Jossey-Bass.

Murray, D. J. (1981). Microstates: Public administration for the small and beautiful. Public Administration and Development, 1(3), 245-256. https://doi.org/10.1002/pad.4230010306

Nielsen, M. M. (2016). Digitising a small island state. In Proceedings of the 9th International Conference on Theory and Practice of Electronic Governance, '15-16 (pp. 54-59). New York: ACM. https://doi.org/10.1145/2910019.2910042

Norris, D. F. (2010). E-Government 2020: Plus Ça Change, plus c'est La Meme Chose. Public Administration Review, 70(December), 180-181. https://doi.org/10.1111/j.1540$\underline{6210.2010 .02269 . \mathrm{x}}$

Orlikowski, W. J., \& Baroudi, J. J. (1991). Studying information technology in organizations: Research approaches and assumptions. Information Systems Research, 2(1), 1-28. https://doi.org/10.1287/isre.2.1.1

Pirotta, G. A., Wettenhall, R., \& Briguglio, L. (2001). Governance of small jurisdictions: Guest editors' introduction. Public Organization Review, 1(2), 149-165. https://doi.org/10.1023/A:1011596326871 
Randall, L., \& Berlina, A. (2019). Governing the digital transition in Nordic regions: The human element. Stockholm: Nordregio. https://doi.org/10.30689/r2019:4.1403-2503

Randma-Liiv, T. (2002). Small states and bureaucracy: Challenges for public administration. TRAMES, 6(4), 374-390.

Randma-Liiv, T., \& Sarapuu, K. (2019). Public governance in small states: From paradoxes to research agenda. In A. Massey (ed.). A research agenda for public administration Northampton, MA. Edward Elgar. https://doi.org/10.4337/9781788117258.00016

Richards, J. (1982). Politics in small independent communities: Conflict or consensus? The Journal of Commonwealth \& Comparative Politics, 20(2), 155-171. https://doi.org/10.1080/14662048208447405

Sarapuu, K. (2010). Comparative analysis of state administrations: The size of state as an independent. Halduskultuur: Administrative Culture, 11(1), 30-43.

TAKS (2019). Individual tax. Retrieved from https://www.taks.fo/en/individuals/tax/tax/\#General\%20information\%20about\%20ta xation $\% 20$ in $\% 20$ the $\% 20$ Faroes

Talgildu Føroyar (2019). Heldin. Retrieved from https://heldin.fo/catis

Talgildu Føroyar (2016). Talgildur samleiki: Undirskjal 7 - Mobil ID. Retrieved from https://d3pnpprk515r42.cloudfront.net/media/1045/undirskjal-7-mobil-id.pdf

Talgildu Føroyar (2015). The national digitalisation programme of the Faroe Islands. Retrieved from https://d3pnpprk515r42.cloudfront.net/media/1990/digital-strategy-v1.pdf

Torres, L., Pina, V., \& Royo, S. (2005). E-government and the transformation of public administrations in EU countries: Beyond NPM or just a second wave of reforms? Online Information Review, 29(5), 531-553. https://doi.org/10.1108/14684520510628918

Umhvørvisstovan (2019). Føroyakort. Retrieved from https://www.føroyakort.fo/

United Nations (2018). United Nations e-government survey 2018. United Nations. https://doi.org/10.18356/5dbe3354-en

Útlendingastovan (2017). New to the Faroe Islands: Practical information from public agencies. Tórshavn: Útlendingastovan.

Visit Faroe Islands. (2017). Faroe Islands translate. Retrieved from https://www.faroeislandstranslate.com/\#!/

Yang, K., \& Rho, S. Y. (2007). E-government for better performance: Promises, realities, and challenges. International Journal of Public Administration, 30(11), 1197-1217. https://doi.org/10.1080/01900690701225556

Yazan, B. (2015). The qualitative report: Three approaches to case study methods in education: Yin, Merriam, and Stake. Retrieved from http://www.nova.edu/ssss/QR/QR20/2/yazan1.pdf

Yin, R. K. (1989). Case study research: Design and methods. Newbury Park: Sage. 


\section{Keegan McBride}

\section{Appendix}

\begin{tabular}{|l|l|l|l|}
\hline$\#$ & Name & Title & Area \\
\hline 1 & Nicolai Balle & Program Manager, Talgildu Føroyar & Government \\
\hline 2 & Diana Gilstón & Manager of Customer Support, TAKS & Government \\
\hline 3 & Lars Black & IT Manager, Tórshavn & Municipality \\
\hline 4 & Jóanis Køtlum & Manager of Faroese Hospital System & Government \\
\hline 5 & Ulla Joensen & CEO, Elektron & Private \\
\hline 6 & Poula Lidarenda & Manager of Business Tax, TAKS & Government \\
\hline 7 & Gert Joenson & Head of Software Solutions, Formula & Private \\
\hline 8 & Gilli Wardum & Department Head, Faroese Statistical Office & Government \\
\hline 9 & Jósup Henriksen & Legal Advisor, Talgildu Føroyar & Government \\
\hline 10 & Ann Damgaard & Project Manager, TAKS & Government \\
\hline 11 & Jan Ziskasen & CEO, Føroya Tele & Private \\
\hline 12 & Sofus Johannesen & Project Manager, TAKS & Government \\
\hline 13 & Petur Nielsen & Director, Ministry of Environment & Government \\
\hline 14 & Ólavur Ellefsen & Chairman, Klintra & Private/Academia \\
\hline 15 & Jacob Vestegaard & Parliament Member & Government \\
\hline 16 & Ásla Rasmussen & UX Designer, Talgildu Føroyar & Government \\
\hline 17 & Rolf Olsen & elD Project Manager, Talgildu Føroyar & Government \\
\hline 18 & Leif Abrahamsen & Head of Gjaldstovan & Government \\
\hline 19 & Heini Hátún & Basic Data Project Manager, Talgildu Føroyar & Government \\
\hline 20 & Helena Højgaard & Head of HR, TAKS & Government \\
\hline 21 & Jóhannes Miðskarð & Associate Professor, Setur & Citizen/Academia \\
\hline 22 & Johan Heinesen & Head of Citizen Tax, TAKS & Government \\
\hline 23 & Kristina Háfoss & Minister of Finance & Government \\
\hline
\end{tabular}

